\title{
Mechanisms of Quaternary climate change: Stability of warm phases in the past and in the future
}

\section{European Science Foundation - Austrian Science Fund Conference with the University of Innsbruck - Obergurgl, Austria, 6-11 June 2009}

Carlo Barbante $^{1}$ and Hubertus Fischer ${ }^{2}$

${ }^{1}$ Environmental Sciences Department and Institute for the Dynamics of Environmental Processes-CNR, University of Venice, Italy; barbante@unive.it

${ }^{2}$ Climate and Environmental Physics and Oeschger Centre for Climate Change Research, University of Bern, Switzerland

The most important sources of information on past climate change are derived from paleoclimatic records such as marine sediments, terrestrial archives and polar ice cores, as well as from climate models. These archives are highly complementary, giving a wealth of precious quantitative information on the nature and causes of climate variability and change.

To critically look at climate variability during past interglacials (IGs), approx. 100 scientists from five continents gathered at the Obergurgl University Centre, Austria for this ESF-FWF Conference in partnership with the University of Innsbruck.

The Conference was structured along six sessions on different emerging topics in the field of past IGs. The first session addressed the comparison of different IGs over the last million years, with some specific talks on how IGs are recorded in different climatic archives such as ice cores, marine sediments and terrestrial archives. The role of orbital parameters and feedback mechanisms emerged as key factors in the regulation of past climate during IGs, however, a consistent self-sustained model-based hypothesis is still lacking.

The second session covered the variability and stability of warm phases. Shortterm variability, reconstructed thanks to the high-resolution analyses of ice cores and other archives, has shown that IGs are not as stable as initially thought, and that regional variations in the climatic archives have to be clearly addressed in order to better understand the variability of the climate systems during these periods.

Problems arising from modeling the climate of warm phases were addressed in the third session, in an attempt to improve the prediction of future scenarios. In particular, the dynamics of vegetation and the carbon cycle during the present and past IGs were discussed. It emerged that investigations on this topic must be based on high quality atmospheric $\mathrm{CO}_{2}$ and carbon isotope data, as well as on marine archives for carbonate production and paleoproductivity. Accordingly, one of the highlights of the conference that fuelled intense discussions was the presentation of the first high-precision Holocene

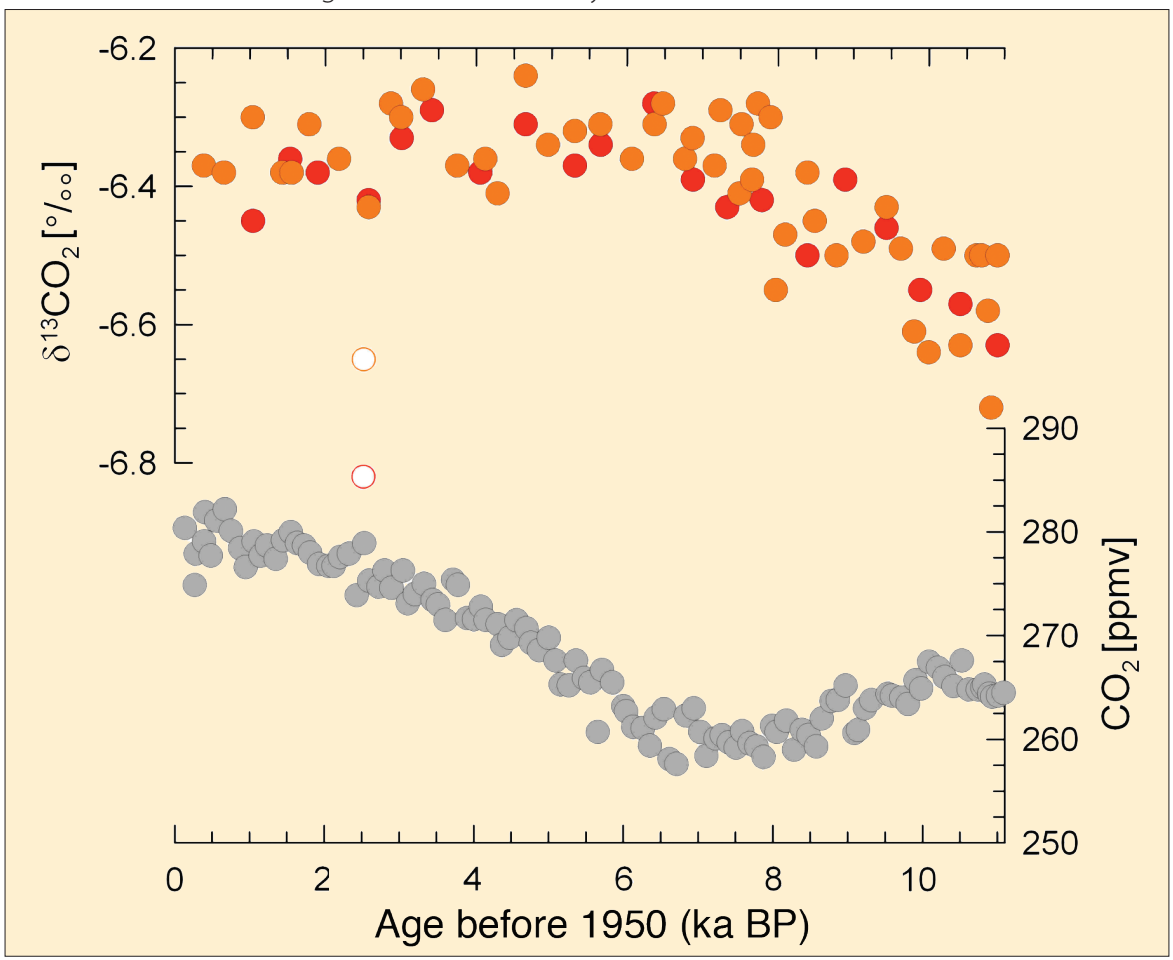

Figure 1: $\delta^{13} \mathrm{CO}$ (red (sublimation method), orange (Cracker method), and white (outliers) circles; Elsig et al., 2009) and $\mathrm{CO}_{2}$ concentrations (gray circles; Monnin et al., 2001; Flückiger et al., 2002) measured in air trapped in ice from Dome C, Antarctica, during the Holocene (Figure modified from Elsig et al., 2009).

isotopic greenhouse gas record (e.g., Fig. 1; Elsig et al., 2009).

The response of ice sheets to interglacial warming and their impact on sea level was the subject of the fourth session of the conference. Past changes in sea level were heavily influenced by the waxing and waning of the large Northern Hemisphere continental ice sheets, and thus cannot provide a direct analog for the sea-level rise in the future. However, it emerged from discussions that it is difficult to project sea level rise in response to ongoing global warming if the past response of the Greenland and Antarctic ice sheets to warming cannot be better quantified. The close combination of paleoclimatic data analyses and modeling efforts will strongly help to put the evolution of present sea level rise in the right perspective.

A modeling session then paved the way for discussion on how and when the present interglacial, the Holocene, would end. Several hypotheses, based on orbital and anthropogenic forcing were addressed, pointing out that further high spatial and temporal resolution models are needed to better understand the processes that will drive the inception of a new ice era.

Finally, the role of socio-economic aspects and impacts of climate change were addressed through specific talks in a dedicated session and open discussions. This session stressed the need for close collaboration between scientists involved in paleodata production and analyses, and scientists working in the field of climate change impact at the socio-economic level.

A "Forward Look" Plenary Discussion was organized with the aim to develop a vision on how climate sciences should evolve in the coming years. Many themes for future research in the field of paleoclimate emerged from the discussion, in particular key issues relating to sea level change and modeling during IGs, and the duration of the present IG. The latter point appears crucial considering that current $\mathrm{CO}_{2}$ concentrations have taken us out of the Quaternary range, putting us in a new era, the Anthropocene. 
Elsig, J., Schmitt, J., Leuenberger, D., Schneider, R., Eyer, M., Leuenberger, M., Joos, F., Fischer, H. and Stocker, T., 2009: Stable isotope constraints on Holocene carbon cycle changes from an Antarctic ice core, Nature, 461: 507-510.
Monnin, E., Indermühle, A., Dällenbach, A., Flückiger, J., Stauffer, B., Stocker, T., Raynaud, D. and Barnola, J.-M., 2001: Atmospheric $\mathrm{CO}$ concentrations over the last glacial termination, Science, 291: $112-114$.
Flückiger, J., Monnin, E., Stauffer, B., Schwander, Stocker, T., Chappellaz, J., Raynaud, D. and Barnola, J.-M., 2002: High-resolution Holocene $\mathrm{N}, 0$ ice core record and its relationship with $\mathrm{CH}_{2}$ and $\mathrm{CO}_{2}, \mathrm{Global}$ Bíogeochemical Cycles, 16: 1010, doi:10.1029/2001GBo01417.

\title{
Towards a global synthesis of the climate of the last two
} millennium

\section{Workshop of the PAGES 2k Regional Network - Corvallis, USA, 7 July 2009}

\author{
Louise Newman ${ }^{1}$, H. WAnner ${ }^{2}$ and T. Kiefer ${ }^{1}$
}

1PAGES International Project Office, Bern, Switzerland; newman@pages.unibe.ch

²Oeschger Centre for Climate Change Research and Institute of Geography, University of Bern, Switzerland; heinz.wanner@giub.unibe.ch

Research on the last 1-2 ka has resulted in several multi-proxy reconstructions of global and hemispheric temperature, and other climatic parameters (e.g., Rutherford et al., 2005; Mann et al., 2006; 2008; Luterbacher et al., 2004). Despite this, we still do not sufficiently understand the precise sequence of changes related to regional climate forcings, internal variability, system feedbacks, and the responses of surface climate, land-cover, biosphere and hydrosphere. Furthermore, many parts of the globe lack adequate paleorecords for comparison with model simulations, and high-resolution instrumental datasets are sparse.
To address these knowledge gaps, PAGES developed the Regional 2k Network-a set of Working Groups (WGs) that collect and process the best available time series and spatial reconstructions of important climate system variables for a given region (including the adjacent ocean; Fig. 1). Several WGs built on existing projects and are, therefore, at a mature stage in their research, while other WGs have only recently formed. All the WGs recently came together for a one-day workshop in Corvallis, USA to discuss regional results, exchange information on approaches and techniques, and develop a coordinated strategy for outcomes and syntheses.

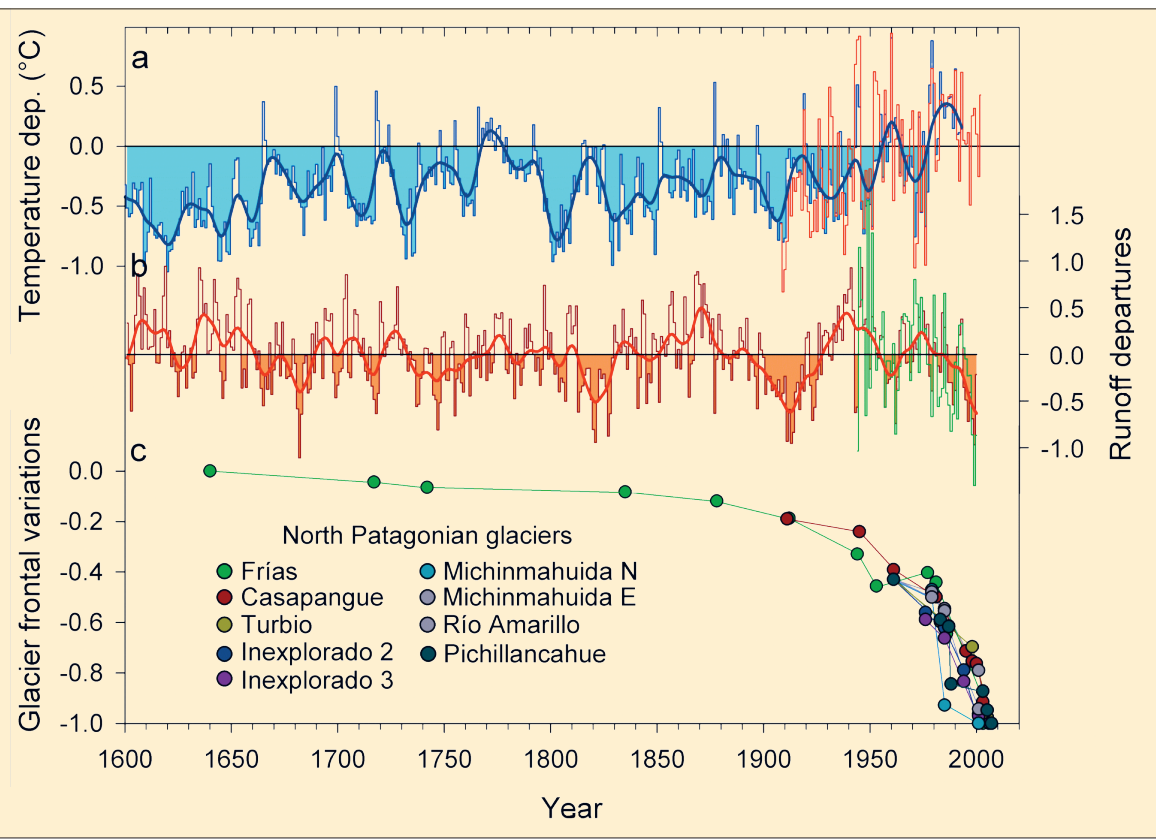

Figure 1: Recent results from the LOTRED-South America 2k effort. Climate variations in the Northern Patagonian Andes during the past four centuries. a) Summer (Nov - Mar) temperature changes (expressed as departure from calibration period 1908-2003) inferred from a regional network of Fitzroya cupressoides tree-ring chronologies in northern Patagonia (blue line; Villalba et al.,2006) plotted with the instrumental summer temperature variations for northern Patagonia (red line; Jones and Moberg, 2003) for the interval 1908-2003. The correlation coefficient observed v's reconstructed is $r=0.75(n=85, p<0.01)$. $\boldsymbol{b}$ ) Tree-ring based reconstruction of Dec-May stream flow deviations (expressed as departure from calibration period 1943-1999) of Río Puelo from 1599 to 1999 developed from a combination of Austrocedrus chilensis and Pilgerodendron uviferum chronologies (red line; Lara et al., 2008). It correlates significantly with the instrumental Rio Puelo stream flow recorded at Carrera Basilio, Chile (green line) for the period 1943-1999, at 99\% confidence level ( $r=0.65$ ). Thick lines in both a and b represent 15-year cubic splines to emphasize low frequency variations in the reconstructions. c) Frontal variations of selected glaciers in the North Patagonian Andes. Total retreat of the glacier with the longest record (Glaciar Frias; AD 1660-2007) was normalized to -1.0 and the frontal variations of the other glaciers were adjusted to this range of variation. Glacier frontal variations are from Villalba et al., (1990), Bown and Rivera (2007), and Masiokas et al. (2008; 2009). The thin interpolation-lines in (c) are drawn to enhance the readability and do not suggest linear trends between two data points.
Following an introductory talk by Heinz Wanner, the state-of-the-science for each group was presented. Representing Europe and the Mediterranean, Jürg Luterbacher presented a compilation of annual- and lower-resolution proxy records, and highlighted efforts towards spatial reconstructions and associated uncertainty estimates for a dynamical understanding of European climate. The focus of this WG now is to push the temporal scale of spatial reconstructions to cover $2 \mathrm{ka}$, combining all available proxies, data-model comparison and data assimilation exercises.

The North American WG is also well placed to move towards synthesis. Caspar Ammann highlighted the extensive network of proxy records available and outlined new methodological advances that will provide greater understanding of the physical mechanisms behind past climatic changes. Future goals of this WG are to produce a review of the available data and to cross validate with model output.

A concerted South American effort has resulted in a recently published series of regional syntheses of data sets from a variety of paleoclimate archives (see details on website). Ricardo Villalba presented an overview of these results, and showed that the spatial and temporal coverage of the data is adequate to develop multi-proxy field reconstructions for southern South America for the past ca. 500 years. Efforts are now being directed towards homogenizing instrumental data sets for calibration of proxy data series, and increasing their temporal and spatial coverage.

The Asia 2k WG is under development. Edward Cook presented multi-proxy reconstructions of the Asian monsoon, temperature and drought from Eastern Asia, the Altay Mountains and Indochina, respectively. The next step for this group is to consolidate the team, followed by a review of the available data and gaps in knowledge. 